Marquette University

e-Publications@Marquette

4-2017

\title{
Profiles of Emotion Regulation: Understanding Regulatory Patterns and The Implications for Posttraumatic Stress
}

Samantha Chesney

Marquette University

Nakia Gordon

Marquette University, nakia.gordon@marquette.edu

Follow this and additional works at: https://epublications.marquette.edu/psych_fac

Part of the Psychology Commons

\section{Recommended Citation}

Chesney, Samantha and Gordon, Nakia, "Profiles of Emotion Regulation: Understanding Regulatory Patterns and The Implications for Posttraumatic Stress" (2017). Psychology Faculty Research and Publications. 208.

https://epublications.marquette.edu/psych_fac/208 


\title{
Profiles of Emotion Regulation: Understanding Regulatory Patterns and The Implications for Posttraumatic Stress
}

\author{
Samantha A. Chesney \\ Psychology Department, Marquette University, \\ Milwaukee, WI \\ Nakia S. Gordon \\ Psychology Department, Marquette University, \\ Milwaukee, WI
}

\begin{abstract}
Trauma survivors often experience posttraumatic stress (PTS) and report concurrent difficulties with emotion regulation (ER). Although individuals typically use multiple regulatory strategies to manage emotion, no studies yet examine the influence of a constellation of strategies on PTS in a community sample. We assessed six ER strategies and investigated whether specific profiles of ER (i.e. the typical pattern of regulation, determined by how often each strategy is used) were related to PTS. A hierarchical cluster analysis indicated that four distinct profiles were present: Adaptive Regulation, Active Regulation, Detached Regulation, and Maladaptive Regulation. Further analyses revealed that an individual's profile was not related to frequency of past trauma, but had the power to differentiate symptom severity for overall PTS and each symptom cluster of posttraumatic permission has been granted for this version to appear in e-Publications@Marquette. Taylor \& Francis (Routledge) does not grant permission for this article to be further copied/distributed or hosted elsewhere without the express permission from Taylor \& Francis (Routledge).
\end{abstract}


NOT THE PUBLISHED VERSION; this is the author's final, peer-reviewed manuscript. The published version may be accessed by following the link in the citation at the bottom of the page.

stress disorder. These findings highlight how profiles characterising multiple regulatory strategies offer a more complete understanding of the ways ER can account for PTS.

Keywords: Emotion regulation, regulatory profiles, posttraumatic stress, trauma

The regularity of traumatic experiences implores us to gain a better understanding of posttraumatic health concerns, such as the development of posttraumatic stress (PTS) symptoms that characterise posttraumatic stress disorder (PTSD). A variety of trauma characteristics (e.g. trauma type; Ehring \& Quack, 2010) and individual factors (e.g. social support, prolonged trauma exposure; Stevens et al., 2013) have consistently emerged as significant contributors to PTS symptom variability in community samples. More nuanced factors, including how people regulate their emotions after a traumatic event, also influence PTS (Stevens et al., 2013) but have yet to be thoroughly explored. Specifically, investigations linking emotion regulation (ER) to PTS have not consistently demonstrated how multiple, distinct strategies work together to contribute to psychopathology. Considering findings that individuals typically use multiple ER strategies (Brans, Koval, Verduyn, Lim, \& Kuppens, 2013), the dearth of studies investigating ER in this way leaves a critical gap in the literature. Moreover, those researchers who have initiated studies to better understand ER in a multidimensional way (e.g. DixonGordon, Aldao, \& De Los Reyes, 2014; Eftekhari, Zoellner, \& Vigil, 2009) have relied on college samples, which are unlikely to reflect the community on which the majority of PTS and trauma research is based. As such, the present study aimed to investigate how variability in PTS symptom severity in a community sample could be accounted for by the collective use of six ER strategies.

A wide variety of strategies are available to manage the internal experience and external expression of emotions (i.e. ER; Gross \& John, 2003). Although no ER strategy is inherently positive or negative, research shows that some strategies largely reduce PTS symptoms, while others intensify them. Indeed, positive outcomes have been observed for trauma survivors who use acceptance, cognitive reappraisal, and problem solving. For instance, increased acceptance, defined as embracing an emotional reaction without defensiveness or secondary negative emotions, is related to lower symptom severity in permission has been granted for this version to appear in e-Publications@Marquette. Taylor \& Francis (Routledge) does not grant permission for this article to be further copied/distributed or hosted elsewhere without the express permission from Taylor \& Francis (Routledge). 
all three PTS symptom clusters (i.e. re-experiencing, avoidance, and arousal; Tull, Barrett, McMillan, \& Roemer, 2007). Further, cognitive reappraisal-the process of altering the meaning attached to an experience to change its emotional impact-can reliably reduce PTS symptoms by combating the negative appraisal style common in chronic PTS (Boden, Bonn-Miller, Kashdan, Alvarez, \& Gross, 2012). Lastly, problem solving to minimise the negative consequences of an emotional experience through cognitions (brainstorming solutions and planning) or behaviours (seeking information and attempting multiple solutions) prospectively predicts decreased PTS six months posttrauma (Gil, 2005).

Alternatively, use of avoidance, expressive suppression, and rumination is often maladaptive and strongly predicts posttraumatic morbidity and symptom severity. For example, avoidance-cognitive and behavioural efforts to minimise the experience of an emotional situation-is related to increased PTS (Ehring \& Quack, 2010). Expressive suppression (i.e. inhibiting the expression of emotional responses) is not only consistently associated with greater severity in all PTS symptom clusters, but reductions in suppression during treatment significantly account for overall PTS reduction (Boden et al., 2013). Other studies demonstrate that rumination, defined as recurrent, repetitive thoughts that centre on negative emotion states, is positively associated with concurrent, prospective, and long-term PTS (Nolen-Hoeksema \& Morrow, 1991).

These findings demonstrating that PTS symptoms persist by misusing any number of strategies are made further complex by the evidence that regulation is typically achieved with multiple strategies (Brans et al., 2013). Moreover, individuals experiencing intense emotions and elevated distress related to symptoms of psychopathology report still greater variation and frequency of regulatory efforts (Dixon-Gordon et al., 2014). Thus, although research investigating pathology should assess ER as a constellation of strategies, current studies often neglect to measure multiple specific strategies and fail to capture the complexity of regulatory efforts. Currently, less than a dozen empirical studies report findings on three or more strategies of ER, and only a small portion of those report PTS outcomes. Ehring and Quack (2010) used a large, web-based sample 
to show that reappraisal was negatively associated with PTS, whereas emotion suppression and avoidance were both positively related to PTS. Yet, in a different study looking at trauma-exposed undergraduates, PTS symptoms had no significant relationship with reappraisal or emotion suppression (though symptom severity was positively correlated with thought suppression and avoidance; Amstadter \& Vernon, 2008). Moving forward, researchers must clarify how a multidimensional pattern of regulation may be beneficial-or problematic-for managing emotion in a posttraumatic context.

Here, we investigate whether trauma survivors exhibit distinct profiles of ER, defined by the frequency with which an individual typically uses multiple different strategies from a regulation inventory. A previous study examining regulation in this way found that an undergraduate sample's use of cognitive reappraisal and expressive suppression could be classified into one of four groups based on high or low use of each strategy. The combination of high reappraisal/low suppression resulted in the lowest levels of PTS (Eftekhari et al., 2009). Dixon-Gordon and colleagues (2014) evaluated seven ER strategies and found that an undergraduate sample could be classified into five regulatory groups. Their analyses indicated that high regulators (i.e. individuals endorsing high use of all strategies) consistently endorsed the highest levels of generalised anxiety and depression. (PTS was not assessed.) These studies indicate promising results for investigating ER in a multidimensional way. However, these results with undergraduate samples may not generalise to existing community and national studies on trauma.

\section{The current study}

The current study investigated the use of six ER strategies: acceptance, cognitive reappraisal, problem solving, avoidance, expressive suppression, and rumination. To better understand how multidimensional regulation might be employed, we first determined whether we could identify distinct profiles of ER. Given that the two published studies on regulatory profiles utilised undergraduate samples with relatively low (or unmeasured) experiences of trauma, our hypotheses were instead driven by the literature on individual strategies of ER and PTS in community samples. Thus, we 
hypothesised that there would be a group of individuals with a profile characterising frequent use of strategies established as adaptive for PTS (acceptance, cognitive reappraisal, and problem solving), and relatively little use of the strategies established as maladaptive for PTS (avoidance, expressive suppression, and rumination). Furthermore, we hypothesised that another profile would characterise the opposite regulatory pattern (i.e. high maladaptive and low adaptive). Although these two profiles were unlikely to be an exhaustive representation of all possibilities, the limited research in this domain made additional profiles exploratory. Since ER strategies are associated with differential symptom outcomes, we hypothesised that severity of overall PTS, as well as severity within each individual symptom cluster of PTSD, would differ according to the proportions of adaptive and maladaptive strategies in an individual's regulatory profile (e.g. more severe symptoms would be related to profiles with higher proportions of maladaptive strategies).

\section{Method}

\section{Participants}

A sample was recruited to represent a broad urban community with a range of trauma histories (i.e. no trauma to severe trauma). Seventy-two participants were recruited from community sites including a wellness centre ( $32 \%$ of sample), students from a local university ( $11 \%$ of sample), a community outpatient mental health clinic ( $10 \%$ of sample), and other community members via word-ofmouth referral ( $18 \%$ of sample). Thirty additional residents of the same community completed the study online. Participants attested that they were either not currently taking psychotropic medication or, if they were, had attained medication stabilisation (stable dose for greater than six weeks). They were also informed that they must have the ability to read in English at the 8th grade level or higher. Technical errors in online data collection occurred, resulting in the exclusion of two participants and leaving a final analytic sample of 100 individuals.

Participants were $18-76$ years old $(M=39.51, S D=15.18)$, and $58 \%$ were female. Slightly less than half of the participants reported their race as White/Caucasian (46\%; 26\% Black/African American; 
NOT THE PUBLISHED VERSION; this is the author's final, peer-reviewed manuscript. The published version may be accessed by following the link in the citation at the bottom of the page.

12\% Hispanic/Latino; $12 \%$ multiracial; 2\% Asian; and 2\% Native American) and the majority were single (62\%; $28 \%$ married; and $10 \%$ divorced/widowed). The majority of participants (69\%) had some post-secondary education. Most of the sample (55\%) reported part- or full-time employment; only $2 \%$ were full-time students. Annual household income ranged from 0 to 250,000 USD $(M=35,141$, $\mathrm{SD}=47,462)$.

\section{Materials}

A meta-analysis (Aldao, Nolen-Hoeksema, \& Schweizer, 2010) was used to identify the most valid and reliable self-report to measure each ER strategy. To preserve inventory psychometrics, all measures were administered in full. However, only specific subscales were used in the analyses, as outlined below.

\section{Difficulties in Emotion Regulation Scale (Gratz \& Roemer, 2004)}

The Difficulties in Emotion Regulation Scale (DERS) is a 36-item measure designed to assess several factors of ER. Responses to the Non-acceptance of Emotional Responses subscale served to measure Acceptance strategies. Items on this subscale assessed one's ability to accept having an emotional response (e.g. when I'm upset, I become [angry/embarrassed/ashamed] at myself for feeling that way; Cronbach's $a=.90)$. Items were scored as intended by the original authors for all analyses. However, for visual representations, this subscale was reverse scored (i.e. a higher score indicating more acceptance) to more clearly report descriptive statistics.

\section{Emotion Regulation Questionnaire (Gross \& John, 2003)}

The Emotion Regulation Questionnaire (ERQ) is a 10-item measure used to assess routine use of cognitive reappraisal and expressive suppression. The Cognitive Reappraisal subscale was used to assess changing one's thought processes when wanting to feel more or less positive or negative emotion (e.g. when I want to feel more positive emotion, I change the way I'm thinking about the situation; Cronbach's $a=.83$ ). The Expressive Suppression subscale was used to 
assess keeping both positive and negative emotions to oneself and being careful not to express them (even though they may be experiencing them internally; for example, I control my emotions by not expressing them; Cronbach's $a=.77$ ).

\section{Coping Responses Inventory (Moos, 1993)}

The Coping Responses Inventory (CRI) is a 48-item measure assessing coping strategies. Avoidance was assessed by summing the Cognitive Avoidance (Cronbach's $a=.80$ ) and Emotional Discharge (Cronbach's $a=.45$ ) subscales of this measure (following Holahan, Moos, Holahan, Brennan, \& Schutte, 2005). This composite score (Cronbach's $a=.74$ ) indicated how often a respondent makes cognitive (e.g. try not to think about the problem; wish the problem will go away) and behavioural (e.g. keep away from people in general) attempts to avoid dealing directly with a stressor. The Problem Solving subscale (Cronbach's $a=.76$ ) of this measure was used to assess planning and understanding what has to be done before resolving the issue (e.g. try at least two different ways to solve the problem; make a plan of action and follow it).

\section{Cognitive Emotion Regulation Questionnaire (Garnefki \& Kraaij, 2006)}

The Cognitive Emotion Regulation Questionnaire (CERQ) is an 18-item measure used to understand how respondents cope with negative/unpleasant events. This study used the Rumination subscale (Cronbach's $a=.59$ ) to evaluate how often a respondent was preoccupied with repetitive thoughts (e.g. I often think about how $I$ feel about what I have experienced).

\section{PTSD Checklist-Civilian version (Weathers, Litz, Huska, \& Keane, 1994)}

The PTSD Checklist-Civilian version (PCL-C) is a 17-item measure used to evaluate each cluster of PTSD symptoms, ${ }^{1}$ as well as overall level of PTS in both clinical and non-clinical populations (Tull et al., 2007; Weathers et al., 1994). PTSD symptom clusters include reexperiencing symptoms, avoidance/numbing symptoms, and arousal 
symptoms. Cronbach's $a$ for the current sample were as follows: total PTS $a=.92$; re-experiencing symptom subscale $a=.84$; avoidance symptom subscale $a=.88$; and arousal symptom subscale $a=.84$. Symptom cluster and total scores were calculated for this measure by summing the responses for appropriate items.

\section{Trauma History Questionnaire (Green, 1996)}

The Trauma History Questionnaire (THQ) is a 24-item measure designed to screen for exposure to various types of trauma including crime-related events, general traumatic events/disasters (e.g. Have you ever had a serious accident? Have you ever seen someone seriously injured or killed?), physical abuse, and sexual abuse. Participants were asked to identify the frequency of each event's occurrence in their life. Item responses were summed to create two composite scores of total trauma experience: (1) a sum of item frequencies (i.e. $0=$ Never, $1=$ Once, $2=A$ few times, $3=$ Many times) across all 24 items to create a metric of total past trauma frequency and (2) a count of the number of different traumatic events endorsed by an individual (i.e. item responses of Once or more).

\section{Procedure}

Participants were recruited via advertisements, measures were completed using either online or paper forms, and participants received nominal compensation for their time (up to $\$ 20$ in cash/gift cards). The institutional review board approved these procedures and all participants provided informed consent.

\section{Results}

Two participants were strong statistical outliers on the PCL-C ( $z$ scores $=2.8,3.2$ ), bringing into question the overall validity of their responses. Thus, they were removed from all further analyses. The remaining sample of 98 individuals was not significantly different than the original sample on any study variable (other than PTS). Table 1 includes descriptive statistics on self-report ER and trauma variables. 


\section{Trauma descriptives and zero-order analyses}

Nearly all (97\%) participants reported the experience of at least one traumatic event in their lives; $92 \%$ of the sample reported multiple traumas. PTS severity was positively correlated with both the mean number of different traumatic event types experienced $(r=.44$, $p<.001)$ and the mean overall frequency for traumatic events $(r=.49$, $p<.001)$. Analyses assessing the relationship of demographic variables to PTS indicated non-significant relationships between all demographic variables and overall PTS (all $p>.05$ ).

\section{Determining profiles of ER}

\section{Cluster analysis}

A cluster analysis was performed to statistically group participants according to their reported use of six ER strategies (acceptance, cognitive reappraisal, problem solving, avoidance, expressive suppression, and rumination). Although there is no universal guideline for cluster analysis sample size, a related methodology recommends a sample size of at least $2^{k}$, where $k$ specifies the number of clustering variables (Formann, 1984). Thus, the current sample meets the minimum criteria for six clustering variables (requiring at least 64 cases). Scores on ER subscales were used as clustering variables, thus identifying clusters of cases with similar ER patterns. A hierarchical agglomerative method using the squared Euclidean distance measure and Ward's method of clustering sequentially merged cases based on similar regulation, while minimising within-cluster variance. ER subscales were mean standardised, by subtracting the mean score from each individual's score, to ensure equal contribution to classification and preservation of original subscale variance. Previous literature indicates that these analysis parameters provide excellent recovery of known cluster structure (Aldenderfer \& Blashfield, 1984).

\section{Cluster solution}

After examining the agglomeration schedule, the variance ratio criterion, and the dendogram result, a four-cluster result optimised 
multiple criteria for determining a cluster solution. The mean standardised subscale scores for each profile are shown in Figure 1. The clusters were named according to the pattern of regulation that is characterised by each: (1) Adaptive Regulation ( $n=17)$ cluster consisted of participants who reported high levels of adaptive strategies and low levels of maladaptive strategies; (2) Active Regulation ( $n=32$ ) cluster consisted of participants who reported moderately high levels of all strategies, with the exception of lower levels of expressive suppression; (3) Detached Regulation $(n=34)$ cluster also reported moderately high levels of most strategies, with the exceptions of low problem solving and high expressive suppression; and (4) Maladaptive Regulation ( $n=15)$ cluster consisted of participants who reported low levels of adaptive strategies and high levels of maladaptive strategies.

\section{Demographic covariates}

Relationships between demographic variables and the regulatory profiles indicated that the likelihood of having a specific ER profile was dependent on race, Fisher's exact test statistic $=22.64, p=.03$, and gender, $X^{2}(3)=11.63, p=.01$. Specifically, Asian participants were more likely than expected to report an Active profile, and Hispanic participants were more likely to report a Maladaptive profile $(p<.05)$. With regards to gender, males were less likely to report a Maladaptive profile, and more likely to report a Detached profile than females $(p<.05)$.

\section{Trauma history and ER profiles}

A discriminant function analysis was used to determine whether the ER profiles could be predicted from frequency of past traumatic experiences. Past trauma frequency was entered as the main predictor variable, with gender and race entered as covariates, to predict the outcome of profile membership. Three discriminant functions were calculated, with a combined Wilks' $\lambda=.838, X^{2}(9)=16.56, p=.06$, indicating a non-significant association between predictors and groups. After removal of the covariate functions, frequency of trauma history alone indicated an especially poor classification, Wilks' $\lambda>.99$, $X^{2}(1)=.22, p=.64$, Canonical $R^{2}=.049$. Therefore increased 
NOT THE PUBLISHED VERSION; this is the author's final, peer-reviewed manuscript. The published version may be accessed by following the link in the citation at the bottom of the page.

frequency of past traumatic experiences did not significantly predict membership of the ER profiles.

\section{ER profiles and PTS severity}

\section{Overall PTS}

To determine whether there were mean differences in overall PTS symptom severity across the regulatory profiles, a one-way analysis of variance (ANOVA) was conducted. Indeed, symptom severity significantly differed between profiles, $F(3,94)=14.11$, $p<.001, \eta_{\mathrm{p}}^{2}=.31$, observed power $=1.0$. Figure 1 presents mean symptom levels for each profile and Bonferroni-adjusted pairwise comparisons. Results indicated that the Maladaptive profile was associated with more severe PTS symptoms than any other profile, and the Detached profile was associated with more severe PTS than the Adaptive profile. There were no significant differences between the Adaptive and Active profiles, or between the Active and Detached profiles.

\section{PTS symptom clusters}

To determine whether the regulatory profiles were associated with severity of each PTS symptom cluster, a one-way multivariate analysis of variance (MANOVA) assessed for mean differences in reexperiencing, avoidance, and arousal. Omnibus results indicated that cluster symptom severity differed between the regulatory profiles, $F(9$,

$224.05)=4.90, p<.001$, Wilks' $\lambda=.65, \eta_{\mathrm{p}}^{2}=.14$, observed power $=.99$. Analysis of each PTS symptom cluster also revealed significant differences in severity across the profiles (re-experiencing: $F(3,94)=7.28, p=.001, \eta_{\mathrm{p}}^{2}=.19$, observed power $=.98$; avoidance: $F(3,94)=12.05 p<.001, \eta_{\mathrm{p}}^{2}=.28$, observed power $=1.0$; arousal: $F(3,94)=11.31, p<.001, \eta_{\mathrm{p}}^{2}=.27$, observed power $\left.=1.0\right)$. Figure 1 presents the mean symptom levels for each profile and the Bonferroniadjusted pairwise comparisons. For all three symptom clusters, individuals with the Maladaptive profile reported significantly more symptoms than any other profile. Further, for the avoidance symptom permission has been granted for this version to appear in e-Publications@Marquette. Taylor \& Francis (Routledge) does not grant permission for this article to be further copied/distributed or hosted elsewhere without the express permission from Taylor \& Francis (Routledge). 
cluster, individuals in the Detached profile demonstrated more difficulties in this domain than the Adaptive and Active profiles (although still significantly less than the Maladaptive profile).

\section{Discussion}

The current study is the first to relate a multidimensional measure of ER, expressed as profiles, to PTS symptom severity in a community sample. Based on six regulatory strategies, results indicated the presence of four distinct ER profiles: Adaptive Regulation, Active Regulation, Detached Regulation, and Maladaptive Regulation. Overall PTS severity, as well as severity within symptom domains, was significantly different across the regulatory profiles, offering novel empirical perspectives on the relationship between ER and PTS. The current study supports three major previous findings: (1) individuals can be grouped according to their ER; (2) a pattern of regulation relying on adaptive strategies is associated with low levels of psychopathology; and (3) frequent use of multiple strategies is associated with elevated psychological symptoms (Dixon-Gordon et al., 2014; Eftekhari et al., 2009). Contrary to previous studies, the current analysis did not reveal a group of "low regulators" (i.e. those who infrequently use all measured strategies), perhaps due to differences in sample characteristics with which ER is known to vary (e.g. age, gender; Dixon-Gordon et al., 2014). Instead, the current sample supported the finding that community adults regularly use multiple forms of ER (Brans et al., 2013).

\section{ER profiles and PTS}

Although the regulatory profiles were based on assessments of ER alone, they demonstrated a meaningful relationship with individuals' PTS symptom severity: $28 \%$ of PTS symptom variability was accounted for by an individual's regulatory profile. As was predicted from the previous literature (e.g. Eftekhari et al., 2009; Tull et al., 2007), participants with the Adaptive Regulation profile were significantly more likely to have non-clinical, mild levels of PTS symptoms, and participants who had the inverse regulatory profilethe Maladaptive Regulation profile-were significantly more likely to have clinical, severe levels of PTS. 
The remaining ER profiles demonstrate novel relationships between strategies, which may aid in explaining symptom variability. Individuals in the Active Regulation profile frequently employed all ER strategies, except expressive suppression. At this increased level of symptom severity, individuals are experiencing (either consciously or non-consciously) accumulating posttraumatic distress, which is associated with increased variation and magnitude of regulatory effort (Dixon-Gordon et al., 2014). Thus, when emotional distress becomes difficult to ignore, individuals may require a profile that relies on a more diverse variety of strategies than is present in the Adaptive Regulation profile.

Compared to the Active Regulation profile, individuals with the Detached Regulation profile have substantially higher levels of expressive suppression, lower levels of problem solving, and increased severity of PTS symptoms. Researchers have argued that diminished cognitive resources resulting from suppression negatively affects problem solving abilities (Baumeister, Bratslavsky, Muraven, \& Tice, 1998), which supports the conclusion that high suppression in the Detached regulation profile may diminish one's capability to engage in alternative, adaptive problem solving. This has significant implications for an individual's psychosocial health, given that a high level of expressive suppression-coupled with an inhibited likelihood to seek out solutions to problems-likely isolates individuals, detaches them from their social supports, and puts them at risk for severe PTS.

The individual symptom clusters of PTS paralleled the results for overall PTS severity, whereby symptom reports across all symptom clusters were lowest for Adaptive Regulation profile and highest for the Maladaptive Regulation. The Detached Regulation profile also posed a significantly higher risk for avoidance symptoms. Existing studies have linked increased expressive suppression, as seen in the Detached Regulation profile, with a paradoxical increase in negative posttraumatic thoughts and emotions (Gross \& Levenson, 1997), which in turn further exacerbates PTS by increasing avoidance of behaviours that elicit those negative emotions (Litz et al., 1997).

Results indicating that frequency of past trauma was not related to the likelihood of an individual being characterised by a specific 
profile were somewhat unexpected, given previous research showing differences in regulation as a result of trauma (Bardeen, Kumpula, \& Orcutt, 2013). However, the current methods for ER measurement and sample characteristics are notably different and may contribute to why these findings were not replicated. Further, additional variables related to trauma history, such as social support (Stevens et al., 2013), may be crucial for identifying an accurate model of the relationship between trauma and ER profiles.

\section{Limitations and future directions}

One limitation of the current study is that cluster analysis solutions can vary based on clustering methods; therefore, the investigator must discern legitimate groups from groups imposed by the method (Aldenderfer \& Blashfield, 1984). We addressed this limitation by using a priori statistical theory to determine the clustering methods, and the resulting cluster solution was chosen based on ER and trauma theory. Second, due to the sample and recruitment limitations, it cannot be definitively stated that the current results are replicable in independent samples. Thus, the current results would have benefitted from the support of a replication study or a larger sample size. Also, the heterogeneous trauma histories of the current sample made it impossible to draw conclusions regarding differences in type of trauma. Finally, the cross-sectional data were retrospective self-report and inferences regarding causality cannot be made. Therefore, while it may be intuitive to assume that a specific regulatory profile results in particular levels of PTS, the current data are correlational and require consideration of the opposite causal relationship.

Future studies may investigate additional posttraumatic factors (e.g. social support) or PTSD symptom subtypes (e.g. the relationship between the dissociative subtype and the Detached profile) to further explain the ER profiles and the mechanisms underlying posttraumatic regulation. Investigators may also choose to evaluate whether individuals initially find some degree of suppression adaptive (e.g. to serve the goals of communication and social interactions), to better understand functioning in the Detached or Maladaptive Regulation profiles. Finally, the clinical literature would benefit from investigating 
whether treatment informed by research on ER profiles improves patterns of emotional responding common to PTS and enhances treatment efficacy.

\section{Notes}

${ }^{1}$ In line with recent trauma research, we used the PCL-C, which follows criteria set by the Diagnostic and Statistical Manual of Mental Disorders (DSM), 4th ed., text revision. This decision is supported by findings indicating that a PTSD diagnosis, as defined by DSM-5 criteria, can be closely approximated using the PCL-C (Rosellini et al., 2015).

\section{References}

Aldao, A., Nolen-Hoeksema, S., \& Schweizer, S. (2010). Emotion-regulation strategies across psychopathology: A meta-analytic review. Clinical Psychology Review, 30, 217-237. doi:10.1016/j.cpr.2009.11.004

Aldenderfer, M. S., \& Blashfield, R. K. (1984). Cluster analysis. Newbury Park, CA: Sage.

Amstadter, A. B., \& Vernon, L. L. (2008). A preliminary examination of thought suppression, emotion regulation, and coping in a traumaexposed sample. Journal of Aggression, Maltreatment \& Trauma, 17, 279-295. doi:10.1080/10926770802403236

Bardeen, J. R., Kumpula, M. J., \& Orcutt, H. K. (2013). Emotion regulation difficulties as a prospective predictor of posttraumatic stress symptoms following a mass shooting. Journal of Anxiety Disorders, 27, 188-196. doi: $10.1016 /$ j.janxdis.2013.01.003

Baumeister, R. F., Bratslavsky, E., Muraven, M., \& Tice, D. M. (1998). Ego depletion: Is the active self a limited resource? Journal of Personality and Social Psychology, 74, 1252-1265. doi:10.1037/00223514.74.5.1252

Boden, M. T., Bonn-Miller, M. O., Kashdan, T. B., Alvarez, J., \& Gross, J. J. (2012). The interactive effects of emotional clarity and cognitive reappraisal in posttraumatic stress disorder. Journal of Anxiety Disorders, 26(1), 233-238. doi: 10.1016/j.janxdis.2011.11.007

Boden, M. T., Westermann, S., McRae, K., Kuo, J., Alvarez, J., \& Bonn-Miller, M. O. (2013). Emotion regulation and posttraumatic stress disorder: A prospective investigation. Journal of Social and Clinical Psychology, 32(3), 296-314. doi:10.1521/jscp.2013.32.3.296

Brans, K., Koval, P., Verduyn, P., Lim, Y. L., \& Kuppens, P. (2013). The regulation of negative and positive affect in daily life. Emotion, 13, 926-939. doi:10.1037/a0032400 
NOT THE PUBLISHED VERSION; this is the author's final, peer-reviewed manuscript. The published version may be

accessed by following the link in the citation at the bottom of the page.

Dixon-Gordon, K. L., Aldao, A., \& De Los Reyes, A. (2014). Repertoires of emotion regulation: A person-centered approach to assessing emotion regulation strategies and links to psychopathology. Cognition and Emotion, 29, 1314-1325. doi:10.1080/02699931.2014.983046

Eftekhari, A., Zoellner, L. A., \& Vigil, S. A. (2009). Patterns of emotion regulation and psychopathology. Anxiety, Stress, \& Coping, 22, 571586. doi:10.1080/10615800802179860

Ehring, T., \& Quack, D. (2010). Emotion regulation difficulties in trauma survivors: The role of trauma type and PTSD symptom severity. Behavior Therapy, 41, 587-598. doi:10.1016/j.beth.2010.04.004

Formann, A. K. (1984). Die latent-class-analyse: Einführung in Theorie und Anwendung. Weinheim: Beltz.

Garnefski, N., \& Kraaij, V. (2006). Cognitive emotion regulation questionnaire-Development of a short 18 item version (CERQ-short). Personality and Individual Differences, 41, 1045-1053. doi: $10.1016 /$ j.paid. 2006.04 .010

Gil, S. (2005). Coping style in predicting posttraumatic stress disorder among Israeli students. Anxiety, Stress, \& Coping, 18, 351-359. doi: $10.1080 / 10615800500392732$

Gratz, K., \& Roemer, L. (2004). Multidimensional assessment of emotion regulation and dysregulation: Development, factor structure, and initial validation of the difficulties in emotion regulation scale. Journal of Psychopathology and Behavioral Assessment, 26, 41-54. doi:10.1023/B:JOBA.0000007455.08539.94

Green, B. L. (1996). Psychometric review of the trauma history questionnaire (self-report). In B. H. Stamm \& E. M. Varra (Eds.), Measurement of stress, trauma, and adaptation (pp. 366-369). Lutherville, MD: Sidran Press.

Gross, J. J., \& John, O. P. (2003). Individual differences in two emotion regulation processes: Implications for affect, relationships, and wellbeing. Journal of Personality and Social Psychology, 85, 348-362. doi:10.1037/0022-3514.85.2.348

Gross, J. J., \& Levenson, R. W. (1997). Hiding feelings: The acute effects of inhibiting negative and positive emotion. Journal of Abnormal Psychology, 106(1), 95-103. doi: 10.1037/0021-843X.106.1.95

Holahan, C. J., Moos, R. H., Holahan, C. K., Brennan, P. L., \& Schutte, K. K. (2005). Stress generation, avoidance coping, and depressive symptoms: A 10-year model. Journal of Consulting and Clinical Psychology, 73, 658-666. doi:10.1037/0022-006X.73.4.658

Litz, B. T., Schlenger, W. E., Weathers, F. W., Caddell, J. M., Fairbank, J. A., \& La-Vange, L. M. (1997). Predictors of emotional numbing in posttraumatic stress disorder. Journal of Traumatic Stress, 10, 607618.

Cognition and Emotion, Vol. 31, No. 3 (April 2017): pg. 597-606. DOI. This article is @ Taylor \& Francis (Routledge) and permission has been granted for this version to appear in e-Publications@Marquette. Taylor \& Francis (Routledge) does not grant permission for this article to be further copied/distributed or hosted elsewhere without the express permission from Taylor \& Francis (Routledge). 
Moos, R. H. (1993). Coping responses inventory: Adult form manual. Odessa, FL: Psychological Assessment Resources.

Nolen-Hoeksema, S., \& Morrow, J. (1991). A prospective study of depression and posttraumatic stress symptoms after a natural disaster: The 1989 Loma Prieta earthquake. Journal of Personality and Social Psychology, 61(1), 115-121. doi:10.1037/0022-3514.61.1.115

Rosellini, A. J., Stein, M. B., Colpe, L. J., Heeringa, S. G., Petukhova, M. V., \& Kessler, R. C. (2015). Approximating a DSM-5 diagnosis of PTSD using DSM-IV criteria. Depression and Anxiety, 32, 493-501. doi:10.1002/da.22364

Stevens, N. R., Gerhart, J., Goldsmith, R. E., Heath, N. M., Chesney, S. A., \& Hobfoll, S. E. (2013). Emotion regulation difficulties, low social support, and interpersonal violence mediate the link between childhood abuse and posttraumatic stress symptoms. Behavior Therapy, 44, 152-161. doi:10.1016/j.beth.2012.09.003

Tull, M. T., Barrett, H. M., McMillan, E. S., \& Roemer, L. (2007). A preliminary investigation of the relationship between emotion regulation difficulties and posttraumatic stress symptoms. Behavior Therapy, 38, 303-313. doi:10.1016/j.beth.2006.10.001

Weathers, F. W., Litz, B. T., Huska, J. A., \& Keane, T. M. (1994). The PTSD checklist-civilian version. Boston, MA: National Center for PTSD. 
NOT THE PUBLISHED VERSION; this is the author's final, peer-reviewed manuscript. The published version may be accessed by following the link in the citation at the bottom of the page.

Table 1. Descriptive statistics on select subscales and symptom measures $(N=98)$

$$
M \quad \text { SD } \quad \text { Range Number of items } \alpha
$$

Emotion regulation

\begin{tabular}{|c|c|c|c|c|c|}
\hline $\begin{array}{l}\text { Acceptance } \\
\text { (DERS) }\end{array}$ & 23.96 & 5,92 & $6-30$ & 6 & .90 \\
\hline $\begin{array}{l}\text { Cognitive } \\
\text { reappraisal } \\
\text { (ERQ) }\end{array}$ & 29.75 & 7.03 & $6-42$ & 6 & .83 \\
\hline $\begin{array}{l}\text { Problem solving } \\
\text { (CRI) }\end{array}$ & 12.00 & 3.64 & $0-18$ & 6 & .76 \\
\hline Avoidance (CRI) & 14.71 & 6.23 & $0-36$ & 12 & .74 \\
\hline $\begin{array}{l}\text { Expressive } \\
\text { suppression } \\
\text { (ERQ) }\end{array}$ & 14.61 & 5.99 & $4-28$ & 4 & .77 \\
\hline $\begin{array}{l}\text { Rumination } \\
\text { (CERQ) }\end{array}$ & 5.88 & 2.04 & $2-10$ & 2 & .59 \\
\hline $\begin{array}{l}\text { Posttraumatic } \\
\text { stress (PCL-C) }\end{array}$ & 34.93 & 13.84 & $17-85$ & 17 & .92 \\
\hline $\begin{array}{l}\text { Trauma history } \\
\text { (THQ) }\end{array}$ & & & & & \\
\hline $\begin{array}{l}\text { Number of } \\
\text { unique events }\end{array}$ & 6.97 & 4.23 & $0-24$ & - & \\
\hline $\begin{array}{l}\text { Frequency of } \\
\text { events }\end{array}$ & 10.63 & 7.57 & $0-72$ & - & \\
\hline
\end{tabular}

Percent endorsing event type

Sexual trauma 38

Physical tratuma 44

Crime-related 69

trauma

General $\quad 93$

disaster/trauma

Notes: DERS-Non-acceptance subscale was reverse coded such that higher numbers indicate more aceptance. The listed Range depicts the total possible range of the scale.

Cognition and Emotion, Vol. 31, No. 3 (April 2017): pg. 597-606. DOI. This article is @ Taylor \& Francis (Routledge) and permission has been granted for this version to appear in e-Publications@ Marquette. Taylor \& Francis (Routledge) does not grant permission for this article to be further copied/distributed or hosted elsewhere without the express permission from Taylor \& Francis (Routledge). 
Figure 1. Profiles of emotion regulation and Bonferroni comparsions of Mean PTS and trauma for each profile $(N=98)$. Means with differing superscripts are significantly different from each other $(p<.05)$.

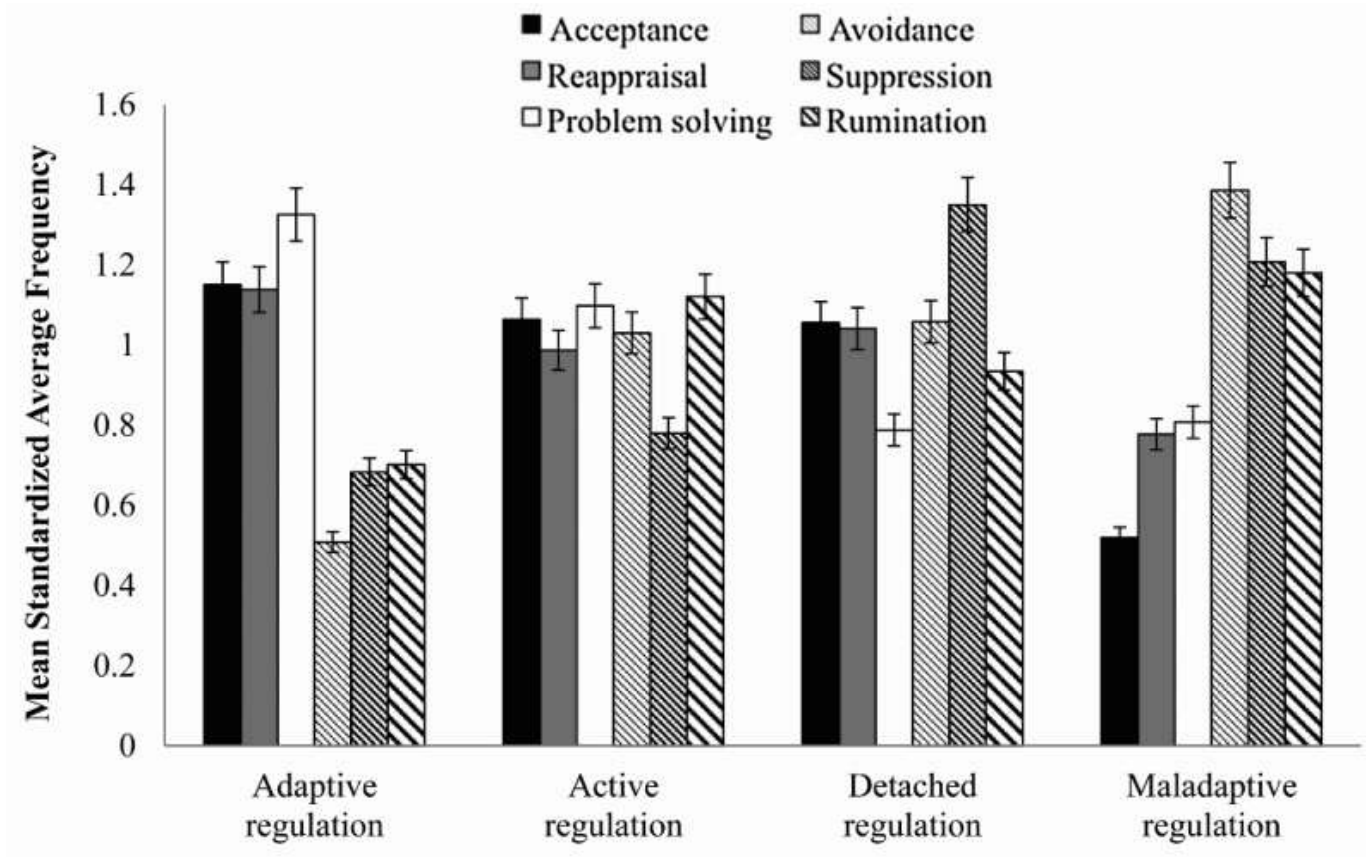

Emotion Regulation Profile

\begin{tabular}{lcccccc}
\hline \multicolumn{7}{c}{$M(S D)$} \\
\cline { 2 - 7 } & $\begin{array}{c}\text { Overall } \\
\text { PTS }\end{array}$ & $\begin{array}{c}\text { Re- } \\
\text { experiencing }\end{array}$ & Avoidance & Arousal & $\begin{array}{c}\text { Types of } \\
\text { trauma }\end{array}$ & $\begin{array}{c}\text { Frequency } \\
\text { of trauma }\end{array}$ \\
\hline $\begin{array}{l}\text { Adaptive } \\
(n=17)\end{array}$ & $\begin{array}{c}26.07^{\mathrm{a}} \\
(8.20)\end{array}$ & $\begin{array}{c}6.82^{\mathrm{a}} \\
(1.98)\end{array}$ & $\begin{array}{c}10.47^{\mathrm{a}} \\
(3.95)\end{array}$ & $\begin{array}{r}8.84^{\mathrm{a}} \\
(4.18)\end{array}$ & $\begin{array}{r}7.59^{\mathrm{a}} \\
(4.29)\end{array}$ & $\begin{array}{c}10.06^{\mathrm{a}} \\
(6.15)\end{array}$ \\
$\begin{array}{l}\text { Active } \\
(n=32)\end{array}$ & $30.37^{\mathrm{ab}}$ & $8.78^{\mathrm{a}}$ & $12.11^{\mathrm{a}}$ & $9.44^{\mathrm{a}}$ & $7.00^{\mathrm{a}}$ & $10.24^{\mathrm{a}}$ \\
$\begin{array}{l}\text { Detached } \\
(n=34)\end{array}$ & $\begin{array}{c}(15.61) \\
\left(13.75^{\mathrm{b}}\right.\end{array}$ & $9.72^{\mathrm{a}}$ & $16.06^{\mathrm{b}}$ & $10.97^{\mathrm{a}}$ & $6.00^{\mathrm{a}}$ & $10.10^{\mathrm{a}}$ \\
$\begin{array}{l}\text { Maladaptive } \\
(n=15)\end{array}$ & $(4.41)$ & $(7.21)$ & $(4.17)$ & $(4.42)$ & $(8.69)$ \\
\hline
\end{tabular}

Cognition and Emotion, Vol. 31, No. 3 (April 2017): pg. 597-606. DOI. This article is @ Taylor \& Francis (Routledge) and permission has been granted for this version to appear in e-Publications@Marquette. Taylor \& Francis (Routledge) does not grant permission for this article to be further copied/distributed or hosted elsewhere without the express permission from Taylor \& Francis (Routledge). 